consider one of the two principal sources of the Amu-daria, the other being the Pianj. According to their statements the Aksu, which waters the Pamir, is an affluent of the Wanj, and doe not fall into the Pianj near Kala Wamar, the affluent of the Pianj being called the Chun'uk-daria, which flows out of the Yashil-kul. In order to assure himself of the truth of these statements Dr. Regel followed the Wanj as far as Tesh-i-Senghi, and he found that the river contained abundance of water. $\mathrm{He}$ intended to spend the winter at Darwaz, in order to resume his explorations in the spring, and it may be hoped that he will succeed in solving the last remaining mysteries of the Pamir.

Mr. S. E. Peal's account of his expedition in 1879 to the Nongyang Lake aud to the pass over the Patkoi Range will be found, with map and panoramic sketches, in Part 2, No. I, of the Bengal Asiatic Society's Fournal for I88r.

THE following despatch has been received at the London office of the New York Herald:- "Irkutsk, February I, 1882, 2.45 p.m. Our three boats left Semenofsky Island on the morning of September I2, bound for Barkin, ninety five miles distant. We got clear of ice at noon. Heavy gale from northeast, and boats dispersed during night; captain's boat, loaded deep, lost mast and sails. We made land on the evening of the $x 7$ th, shoal water. Boat abandoned two miles from beach; party waded and reached deserted village, Saga-tor; 'cachéd' $\log$ books ; proceeded south on the Igth. Delong's last record found reads as follows:--Saturday, October Ist.-Fourteen of the officers and men of the Feannette reached this hut on Wednesday, September 28 , and having been forced to wait for the river to freeze over, are proceeding to cross to the west side this morning on their journey to reach some settlement on the Lena River. 'We have only two days' provisions, but having been fortunate enough thus far to get game in our pressing needs we have no fears for the future. Our party all well, except Ericksen, whose toes have been amputated in consequence of frostbites. Other records will be found in several huts on the east side of the river, along which we have come from the north.-(Signed) GEORGE W. DELONG.' Three subsequent records had been found. Ericksen died October 7 ; party in great distress for food. Noros and Nindemann sent ahead for relief, October 9. They marched south fifteen days, and were found in a starving condition, October 24, by three natives, who took them to a settlement. They could not make themselves understood. News of them reached us October 29. Immediate search commenced, and party traced to a wilderness on left bank of Lena. Natives refused further work, and return to Bulong; was necessary to get Russian assistance. - November 28. - A large party is now searching, having to dig out everything deeply covered with snow. The wilderness devoid of game. Very prompt and efficient action by Russians. Every effort is being made. Jack Cole's tranquil to-day ; violent only at times ; softening of brain. My left eye ruined, and right one badly impaired. Other men well- Jackson has telegraphed me from Orenburg.--JoHN DANENHAUER." Semenofsky Island is probably a small island marked Semenov in the map in the "Voyage of the Vega," on the north-west of Stobovoi Island in the New Siberia group. Barkin is on the north-east point of the Lena delta, where there is a winter tent. Sagastyr, where they landed, is at the mouth of the most northern branch of the Lena delta. The engineer Melville has made arrangements for a thorough search for the missing party, at once.

\section{THE PRIZES OF THE PARIS ACADEMY OF SCIENCES}

THE annual distribution of prizes at the Academy of Sciences took place on Monday February 6. M. Wurtz, president for the year 188I, wes in the chair. The list of laureates was read by M. Dumas.

The prize of $240 l$. for any improvement in the French naval forces was awarded to $M$. Sébert for his apparatus for measuring the velocity of projectiles, and to $\mathbf{M}$. Brault for his study of naval meteorology.

The Lalande Prize was awarded to Prof. Swift of Rochester, (U.S.) for the discovery of seven comets in the brief interval of four years. Another astronomical prize was awarded to Mr. D. Gill, director of the Cape Observatory, for his determination of the solar parallax by observations of Mars.

The prize in Physics was awarded to M. Planté for his accumulators, and the Commission records the wonderful experiment which was executed by this physieist when he obtained a tension of 1200 element; with two Bunsens. Amongst the other prizes which may present some special interest are the following:-M. Briot, for his work, "Sur les Fonctions Abeliennes"; M. Etienne Gilbert, "Etude sur les Philtres, Charmes, Poisons." No prize was awarded for the question "to ascertain by direct observations and experiments the influence of exterior objects on the structure of vegetative organs," but a sum of $60 l$. was delivered to M. Mer to encourage him to work again at the same question which remains open for competition in 1882. One of the Monthyon Prizes was awarded to Dr. Favre for his work on Daltonism, and another to Dr. Paul Richer for a treatise on hystero-epilepsy. M. Collin took the interest of the Breant Prize for his work on "Epidemical Affections." This prize, originally destined for a remedy against cholera, amounts to $4000 l$, and the interest is distributed every year, to avoid indefinite accumulation. A posthumous prize was awarded to M. Henri St. Claire Deville for his discovery of the law of dissociation. The rules forbid the Academy to give such an honour to any of its living members, and it is the first time on record that it has been given to a departed one.

When the long series of laureates was recited, M. Bertrand, perpetual secretary for the section of Mathematical Sciences, read the eloge of Leon Foucault, the inventor of the gyroscope, electric light regulator, siderostat, silvered glass telescopes, determination of velocity of light, \&c. M. Leon Foucault was born in Paris in 1819 , he died in the same city in 1868 , and never travelled abroad. He was self-educated, having passed his honours only when already illustrious. M. Bertrand has written the preface to the collection of his scientific works, published in 1878 by his mother-a large 4 to volume of 600 pages. M. Leon Foucault was besides a very active and successful writer, having been the scientific editor of the Feuilleton of the Debats for years. His succes: or is now M. de Parville.

\section{INSTITUTION OF MECHANICAL ENGINEERS}

THE Annual General Meeting of this Institution was held at the Institution of Civil Engineers, Great George Street, on January 26 and 27 .

The Annual Report of the Council drew attention to the subjects of experimental research, of which some account has already been given in NATURE. With regard to riveted joints, it appears that a long and elaborate series of experiments have been carried on for the Committee by Prof. Kennedy, at the Engineering Laboratory, University College. These experiments dealt excluvively with steel plates and rivets, and were directed first to ascertain the constants of resistance to tension, shearing, \&c., in mild steel, the knowledge of which is necessary in order to design the strongest form of joint, and secondly to test joints designed on the basis of the values thus discovered, as against other joints, made purposely to have an excess or defect in one or other of the areas through which fracture might take place. The work has heen completely successful ; the correctly-designed joints giving decidedly the best results, and thus affording a satisfactory verification of the value determined for the constants. The experiments have further brought out strongly the fact that joints in iron and steel must be designed in a very different manner to give the best results in each, the reason being that the shearing resistance of the rivets is about the same in iron and steel, while the tensile resistance is much higher in the latter than the former. Hence the deduction that manufacturers, who have been content simply to transfer to steel the rules they have been in the habit of using for iron, have thereby involved themselves in serious error.

With regard to the other subject, the hardening and tempering of steel, the Institution have just published some very interesting researches made for them by Prof, Abel, C.B., F.R.S., and also by Prof. Chandler Roberts, F.R.S. The former has shown, by the analysis of thin disks of hardened and unhardened steel, the high probability that in unhardened steel the carbon is present as a definite carbide of iron (probable composition $\mathrm{Fe}_{6} \mathrm{C}_{5}$ ), eliminated from the iron in a more or less crystalline form; that on heating, this compound is dissolved in, or assimilated by, the metal; and that sudden cooling does not allow time for the elimination to take place, the carbide thus remaining dissolved, more or less completely, and giving a corresponding degree of hardness to the mass. Prof. Chandler Roberts' researches bear on a suggestion which had been made, that the hardening of steel was connected with the ccclusion and exclusion of gases by 
the metal, in the process of heating and cooling. This he has shown to be unfounded, by heating steel (previously deprived of all occluded gas) to bright redness in a vacuum tube, and then plunging it in mercury, when it was found to harden just as usual. The same followed when a coil of wire was heated in vacuo by an electric current, to expel the gas, and then quenched in mercury.

The first paper read was by Mr. J. J. Tylor, on meters for registering small flows of water. The many forms of water meter in use are sharply divided into two classes : piston meters, in which the water is made to flow into a cylinder under a piston, and to escape when the cylinder is full, the number of cylinderfuls being measured; and inferential meter:, in which the water is made to turn a fan of some kind, presumably at the same speed as that of the water it elf, and the number of revolutions of this fan is measured. The latter class has often been supposed to be less reliable than the former, especially when the quantity passing is small; but the paper gives the results of several comparative experiments, which show that an inferential meter is at least as accurate as a piston meter for all except the very smallest flows, and that for these neither form is fully to be depended on. In practice, however, it is found that, even in small tenements, little or no water is drawn at so slow a speed as to render meters unreliable. Various tables were given showing the great advantages of the meter as detecting waste, the amount of which, under our present water system, is enormous. Good reason is given for believing that ten gallons per head per day in small houses, and fifteen in large houses, is an ample allowance for the real wants of the population; and yet twenty-seven gal. lons per head is the regular supply of the London water companies. This is probably the most gigantic specimen of organised waste in the world. The means of stopping it are well within the compass of science, and the expense would not be very great; but with the present anarchy in everything connected with metropolitan government, it is, we fear, hopeless to expect the matter to receive attention.

To prevent this waste it is not necessary (as Mr. Tylor pointed out in the discussion) to place a meter in every house. Although many Continental towns are supplied on that system, it would be difficult of introduction in London, and it may be questioned (as various speakers did question) whether it would be worth the expense. The "district meter" system practically accomplishes the same end without this difficulty. On this system a meter is connected with a train of clockwork and drum, so as to register the amount of water passed during successive intervals, say of ten minutes each. The consumption in the different districts of a town, each containing some hundred houses, is measured for 24 hours each, by simply placing the recording meter successively on the mains supplying them. If any of the diagrams thus obtained show special anomalies, the cause can be inquired into: for instance, if a district shows a large quantity of water passing in the small hours of the night, it is obvious that there is serious leakage somewhere; and the inspector proceeds to make a nocturnal tour, and to listen at the stopcocks of each house successively, by which means he can soon detect where the fault lies. In instances given by Mr. Tylor, the use of this simple plan had been effectual in reducing the consumption by fully one-half in particular districts. The system has been applied to the Honses of Parliament; and the consumption of water during some of the prolonged debates of las: session has thus been recorded for the benefit of posterity.

The second paper was by Mr. A. A. Langley (engineer to the Great Eastern Railway), on the system of dredging introduced by M. Bazin, the celebrated hydraulician, on the rivers of France. Nothing can be more simple than this arrangement. An ordinary centrifusal pump is worked on board the dredger, and a flexible pipe leads from the pump to the bottom of the water, where it terminates in an elbow-shaped nozzle. The sand and gravel is sucked up the pipe, passes through the pump, and is conveyed along an open channel to the side of the dredger, where it fall; into a hopper barge or is otherwise disposed of. On this system the water pressure, as will be seen, is used to facilitate the raising of the sand to the surface; whereas in all other dredgers it is a hindrance rather than otherwise. It thus forms an excellent adaptation of scientific principles; and though not applicable fur clay or hard ground, is much cheaper and more rapid than other furms in the removing of sand and shingle. It has also the great advantage that it can be worked in rough water, since a moderate rise and fall of the vessel does not affect the flexible pipe.
There is another point of interest in connection with this dredger. When first started at Lowestoft it was found impos. sible to make it work with anything like speed or economy, owing to the rapid wear of the cheeks and blades of the pump, which were cut by the sand exactly as glass is cut in the sandblast process. After many trials the evil was stopped by the simple process of protecting the blades of the fan by pieces of thick india-rubber, which from its softness and elasticity yields to the cutting action, and thus escapes much injury itself, while it prevents all injury to the cheeks. This peculiar property of india-rubber has, we believe, been previously utilised in connection with the sand-blast process, but it has never been adopted on so large a scale, and it certainly deserves to be very widely known.

In the course of the discussion Mr. Charles Ball, who has worked a large number of these dredgers, mentioned that he had forced sand thus dredged for a distance of 600 yards through horizontal pipes, by the mere action of the pump. To prevent the silt from settling during its passage along open troughs, he had inserted a light ${ }^{*}$ angle iron in an undulating line along the inside of the trough, so as to give the water a continual twisting motion as it travelled onwards. The great difficulty was to prevent the water from ceasing to flow, either from the sand accumulating above the pump, or from old sacks and other rubbish choking the nozzle. The former was got over mainly by making the discharge-pipe horizontal, and giving it a siphon bend, which kept the water always within it, and prevented any difficulty in starting the pump; and the latter by making openings in the nozzle, just above the grating, which were covered by an indiarubber band having slits in it. When the grating got choked and a vacuum began to form inside the nozzle, these slits opened to the pressure, and allowed the water to flow in.

The third paper was by Mr. E. B. Ellington, on hydraulic lifts for passengers and goods. The risks which attend the use of ordinary chain lifts were minutely described, and also the way in which these are removed by the use of direct acting hydraulic lifts, in which the cage rests on the top of a column of pressurewater, both in ascending and descending. The chief difficulty with such lifts is to balance the dead weight of the cage and attachments, so as to save the needless expenditure of power in raising these each time; and an ingenious arrangement of hydraulic cylinders is described, by which this is attained without the use of counter-weights or chains. A table of experiments on lifts of this and other types is given, which shows the efficiency to be very high, ranging from 75 to 80 per cent. The discussion on this paper was adjourned, for want of time, to the next meeting.

\section{THE CHEMISTRY OF BAST FIBRE ${ }^{1}$}

I $\mathrm{N}$ a previous paper isee Chem. News, 43, 77, and Chem. Soc. Four. xxxviii. 666) the authors established the following points :-The chemical similarity between the non-cellulose constituents of monocotyledonous and dicotyledonous fibres; the reiolution of the jute fibre by chlorine into cellulose (using this word in a general sense), and the chloroderivative of an aromatic body, $n\left\{\mathrm{C}_{19} \mathrm{H}_{18} \mathrm{Cl}_{4} \mathrm{O}_{9}\right\}$; all bast fibres examined (flax, hemp, manilla, esparto, \&c.) yielded a similar body; the reactions of this substance suggested the hypothesis that it was a complicated derivative of tetrachlorquinone; jute fibre was resolved by boiling dilute hydrochloric or sulphuric acid into 2 . soluble carbohydrate and an insoluble compound of the aromatic body with the more stable form of the cellulose ; dilute nitric acid resolves the fibre into cellulose and a nitroderivative of the aromatic constituents $n\left\{\mathrm{C}_{25} \mathrm{H}_{31}\left(\mathrm{NO}_{2}\right) \mathrm{O}_{23} \mathrm{H}_{8}\right\}$; no constituent of the nature of pectose was found. From these facts the authors drew the conclusion that jute fibre consists of cellulose intimately associated with a complicated body allied to the yuinones, in fact, a cellulide after the type of the glucosides, the aromatic body being united to cellulose in place of glucose. They also observed that the chlorinated body, when treated with a solution of sodium sulphite, develops a magnificent purple colour; this reaction was applied for the detection of bast fibres. In the present paper the authors have continued this line of research. To the aromatic constituent of the jute fibre the authors assign the formula. $\mathrm{C}_{19} \mathrm{H}_{22} \mathrm{O}_{9}$. The resemblance of this formula to that of catechin, $\mathrm{C}_{19} \mathrm{H}_{18} \mathrm{O}_{8}, 3 \mathrm{H}_{2} \mathrm{O}$, suggested a comparative investigation of the latter substance; both catechin and catechu.

${ }^{x}$ Abstract of papers by C. F. Cross and E. J. Bevan at the Chemieal Society, January 19. 